\title{
La administración pública del futuro (horizonte 2050). Instituciones, política, mercado y sociedad de la Información.
}

\author{
Carles Ramió \\ (2017) Tecnos \\ Madrid, $241 \mathrm{pp}$.
}

\author{
Cecilia Güemes \\ Universidad Carlos III de Madrid/GIGAPP \\ cecilia.quemes@gigapp.org
}

DOI: https://doi.org/10.20318/eunomia.2018.4178

¿Por qué y para qué un libro que reflexiona sobre el futuro de la Administración Pública en tiempos donde Google o Amazon parecen dominar el juego en un escenario de $4^{\mathrm{a}}$ revolución industrial, hiper-personalización de los productos y servificación de la economía ${ }^{1}$, y el Estado tiene un rol cuanto menos rezagado y/o anecdótico en la era de lo global? La respuesta a ello, ya la daban los clásicos de la sociología. Para empezar, porque pese a los pronósticos que desde hace más de un siglo auguran su pérdida de sentido y posterior desaparición, la burocracia sigue siendo relevante e inevitablemente necesaria en la gestión de lo social, como bien destacara Weber ${ }^{2}$. Para seguir, porque necesitamos un actor capaz de coordinar la conducta colectiva, moralizar las reglas del juego y garantizar los derechos civiles, políticos y sociales creados y organizados por el Estado frente actores externos inescrupulosos e individuos que velan por su propio interés, nos agregaría Durkheim ${ }^{3}$.

Asumida esta premisa, el libro de Carles Ramió aporta claves sobre cómo reformar y a la vez resignificar una Administración Pública catatónica, que ha perdido capacidad de respuesta y busca sobrevivir en un contexto de crisis de Estado, donde

\footnotetext{
1 Juan Pedro Moreno, "Una economía digital que revolucionará la industria", El País, Cinco días, 21 de septiembre de 2017 Disponible en: https://cincodias.elpais.com/cincodias/2017/09/20/companias/1505925329 715905.html?id externo rs oc=TW CC

2 “Quién tendría que ser entonces el que se hiciera cargo de esta nueva economía y tomara su mando?” se preguntaba Max Weber en 1918 (El socialismo) advirtiendo cómo el futuro comunismo vería desplazada la dictadura del proletariado por la del funcionariado. La desaparición del Estado estaba lejos de hacerse realidad.

${ }^{3} \mathrm{Si}$ el origen histórico del Estado estuvo orientado hacia fuera, ahora la actividad interna que lo reclama no es económica ni mercantil si no moral. Durkheim, E. (2003), Lecciones de sociología. Física de las costumbres y del derecho y otros escritos sobre el individualismo, los intelectuales y la democracia, Miño y Dávila editores, Buenos Aires.
} 
el neoliberalismo, la gobernanza vacía, y la tecnocracia se disputan la gestión de los derechos ciudadanos.

El trabajo tiene claramente dos partes, a nuestro entender. La primera, es un análisis de las variables independientes o causas exógenas que afectan a la Administración Pública. Allí se dialoga con investigaciones provenientes de otros campos científicos como la economía, la sociología y la psicología, y se describe y detalla: el impacto de los cambios tecnológicos, los condicionamientos que delinea el postcapitalismo, la globalización y la internacionalización de los flujos comerciales (pp. 33 y 53), el creciente poder de Oriente sobre Occidente, la sensación de absoluta incertidumbre e inseguridad a la que se enfrentan los ciudadanos en su día a día, los retos globales que impondrá el crecimiento demográfico (p.38), el cambio climático derivado, la tensión entre el relato mágico del populismo y de la demagogia de cara a un déficit de liderazgo político (p. 47) y las brutales desigualdades sociales que se van imponiendo (p. 67).

Estos factores externos se articulan negativamente con factores endógenos a la propia Administración Pública (p. 91). En primer lugar, está la omnipresente crisis del Estado Nación que puede sobrevivir agónicamente bajo el principio de legalidad pero le cuesta lograrlo de forma democrática sin recurrir a los chamanes y las lógicas demagógicas en un contexto de dificultosa supervivencia fiscal -especialmente si se tiene en cuenta el gasto en pensiones y sanidad que aumenta exponencialmente (pp. 117, 172). Por un lado, se vislumbra un Estado Nación que intenta coordinarse con otros Estados y formar macro-regiones para atender cuestiones como el cambio climático, los paraísos fiscales o el terrorismo, a la vez que disciplinar a los poderes fácticos monopólicos. Por el otro, las ciudades se vislumbran como los actores históricos de la época revitalizando la democracia en tanto recrean ágoras y asumen una conexión des-intermediada con el ciudadano, aunque el peligro de la fragmentación es real y el temor de volver a regímenes feudales de ciudades Estados que compiten entre sí, inquietante (pp.18, 35). En segundo lugar, está la corrupción, reto mundial que solo puede ser inoculado mediante nuevas instituciones pero también apelando al desarrollo de valores públicos en pos del desarrollo de la cultura cívica (pp. 220). En tercer término, el modelo burocrático-meritocrático, formación geológica marcada por sistema de pliegues y fallas que hacen que domine un tipo híbrido donde el clientelismo y el patronazgo (modelo premoderno) resurgen recurrentemente, a la vez que los modelos gerenciales desmantelan los valores públicos.

Así, en tiempos de "capitalismo voraz con matices moralistas" donde se conjuga el imperio de lógicas monopólicas, con una economía colaborativa bicéfala en la que una de sus cabezas busca volver al trueque y apunta a la gratuidad, mientras la otra arrasa con los mercados sin respetar ninguna regla de forma depredadora y sin escrúpulos (pp. 69 y 209)-, las debilitadas administraciones tratan de anticipar las demandas políticas de "ciudadanos cultos universales" bajo un "tsunami de crispación, sensación de inseguridad y temor social (p. 74)".

Imaginar cómo puede y cómo debería ser la Administración pública a largo plazo, abre para el autor tres escenarios: uno reactivo, donde se pierde y cede la dirección de la gobernanza a los actores privados; otro proactivo, donde la inversión en conocimiento e inteligencia institucional permite llevar las riendas ${ }^{4}$; y un último

\footnotetext{
${ }^{4}$ Estas posturas casan bastante con el trabajo de Linda Weiss (2003) States in the global economy. Bringing domestic institutions back, in Cambridge University Press, el cual, contradiciendo a quienes sugerían una dilución del poder y un vaciamiento o ahuecamiento (hollowing out) del Estado y sus capacidades frente al macro poder que ganaban otros actores (discurso muy funcional con la strait-jacket neoliberal), ofrecía un cuadro más realista de los procesos actuales e introducía una nueva mirada
} 
ofensivo, donde el miedo de los ciudadanos y la colisión con intereses de las empresas conduce a una recuperación protagónica del poder por parte del Estado.

Si el escenario más realista es el segundo, y a lo que hay que apuntar es a ser proactivo y llevar las riendas, la pregunta que se impone es: ¿cómo?, o en otras palabras: ¿qué debe hacerse para que administraciones públicas que se comportan como conejos y deambulan a un ritmo de caracol, cuando no de cangrejo (con importantes regresiones) o se inmovilizan como el mejillón, puedan seguirle el ritmo a los gatos (empresas), las ardillas (cooperativas y organizaciones sin ánimo de lucro) y los tigres (multinacionales) (pp. 21 y 198)?

La segunda parte del trabajo se centra en aportar claves para responder a dicha pregunta partiendo de la premisa de que la innovación en la Administración Pública no es un oxímoron propio de Borges sino justo lo contrario ${ }^{5}$. Por ello, bajo el denominado modelo buroempresarial, el autor analiza críticamente el estado actual de la burocracia a la vez que introduce luces donde poner la atención para el desarrollo de la inteligencia e innovación. La propuesta esbozada es una mezcla ordenada del modelo burocrático y el modelo gerencial pero con valores públicos, donde se empresarializa la mayor parte de la Administración Pública para ganar flexibilidad, pero bajo una transparencia controlada socialmente y un control público del modelo -basado en la jerarquía- con amplia capacidad para rendir cuentas (pp. 144 y 149). Todo aquel que haya renegado de la Nueva Gestión Pública y, por lo tanto, se sienta horrorizado ante la palabra empresarialización de la Administración, no debe temer y está obligado a leer los capítulos 4, 6 y 7 con especial atención. Lejos de asistirse a un remake de la Nueva Gestión Pública y planteamientos neoliberales se discute críticamente, con claridad y conocimiento de causa, una reforma de la institución pública capaz de revitalizarla, darle agilidad, inteligencia y relevancia bajo valores públicos y siempre al alero de la justicia social y la equidad como referentes.

En términos operativos, bajo este modelo se buscaría:

a) la máxima flexibilidad en la gestión y dirección, a fin de ser permeables a la innovación y el aprendizaje ("no pueden alcanzase estándares de cocina creativa del tipo restaurantes el Bullí trabajando bajo protocolos propios de McDonalds", pp. 145); b) aportar la seguridad jurídica e institucional que la sociedad requiere, ("buena parte de la administración pública que opera proveyendo servicios públicos sí debe operar como un McDonalds si quiere garantizar el mismo trato y tipo de servicio y calidad a todos los ciudadanos", pp. 146);

c) flexibilizar los sistemas de contratación y compras para lograr máxima economía y eficiencia pero aprovechando los sistemas de gestión digital y de control ex ante, durante y ex post, (pp.148);

d) mantener una selección y dirección pública profesional basada en la meritocracia, especialmente en todos aquellos espacios administrativos que guardan relación con el valor institucional como son los sistemas de justicia, organismos de control, actuación policial, etc., donde se mantenga un sistema disciplinario efectivo (pp. 153154).

\footnotetext{
respecto a los efectos de la globalización, descubriendo una nueva cara "posibilitante" (enabling side), destacando el significativo margen de maniobra con el que aún cuentan los Estados.

${ }^{5}$ La innovación en el último siglo ha estado guiada y dirigida por el Estado, sirva como ejemplo la industria aeronáutica, de las computadoras, de los semiconductores o de la batería de litio. La historia ha demostrado que cuando los riesgos son demasiado grandes, los resultados inciertos o comercialmente poco viables, las empresas privadas dudan en arriesgar el dinero para financiar innovación y son los gobiernos quienes apuestan. Aunque usted no lo crea, la innovación pública ocurre la mayor parte del tiempo. Ken Boxer, (2014) "At the crossroads of public service and innovation" Govloop. Disponible en: https://www.govloop.com/community/blog/at-the-crossroads-of-public-service-and-innovation/
} 
El autor imagina que la administración pública del futuro va a poseer menos empleados públicos que la actual; se mantendrán los cargos de gestión pero el personal de apoyo irá desapareciendo en tanto aporta menor valor añadido a la par que surgirán nuevos perfiles profesionales como los gestores de información, capaces de buscar y tratar la información crítica, sistematizarla y anticipar problemas (pp. 157). Con mucha lógica y sin miedo a represarías, el autor afirma que no tiene mucho sentido que el mercado público retribuya mejor que el privado en los puestos operativos e instrumentales, que son los que aportan menor valor agregado, y retribuya por debajo del privado a los puestos más elevados que son los que aportan más valor público e inteligencia institucional, pues esto nos aboca a la desprofesionalización y nos hace permeables a la corrupción (pp. 177-178). Por tanto, se hace necesario suprimir privilegios laborales, eliminar las rigideces garantistas (exigiéndose a los empleados públicos la misma disciplina y nivel de rendimiento de los empleados privados) y apostar por adquirir mayor información e inteligencia institucional (pp. 179). Asimismo, y sumado al aprovechamiento de información y gestión inteligente, se necesita regular los servicios universales de interés general, definiendo claramente cuáles son los servicios de interés general (agua, electricidad, salud, educación, transportes, pensiones, sistema bancario, etc.) y mejorando los mecanismos de control de la gestión privada de todos ellos, lo que incluye la creación de agencias especializadas en gestión de la externalización (pp. 196).

Por último, el libro concluye con una propuesta de diseño organizativo muy atractiva a la par que provocadora donde la organización se articula entre:

- unidades centrales de carácter político y de inteligencia, formada por los nuevos funcionarios públicos de origen político pero con conocimientos sobre gestión pública, valores públicos e inteligencia estratégica y los directivos públicos profesionales;

- parques logísticos de servicios públicos, parecidos a parques industriales o ciudades corporativas o campus universitarios, donde se organicen por sectores de políticas y servicios públicos agencias públicas independientes;

- cuatro tipos instituciones públicas: órganos de carácter político y de participación, centros educativos, centros sanitarios y comisarías con efectivos policiales ( $\mathrm{pp}$. 231-233).

La idea es fragmentar a pequeña escala la política e integrar en economías de escala la gestión de las políticas y de los servicios; si la imagen de futuro será una red de barcos autónomos le va a corresponder a la Administración Pública articular estos barcos y dirigirlos como una flotilla (pp. 234 y 241).

Ahora bien, todo este cambio organizativo debe responder a una agenda de nuevos valores que va más allá de clamar por la innovación o la equidad social e incluye valores como: la sostenibilidad, la salud, la vigilancia ante la corrupción, la transparencia y rendición de cuentas (no solo para las Administraciones públicas sino también para las empresas), el fomento del aprendizaje, la coherencia política, la igualdad de género, la sostenibilidad intergeneracional, el big data, la regulación equilibrada, la identidad digna o la privacidad personal (pp. 224).

Antes de cerrar esta reseña enumerando las virtudes del texto y del autor, me gustaría abrir un paréntesis sobre dos de los problemas endógenos a los que refiere el autor: los dilemas fiscales a los que se enfrentan los Estados y el reto universal de la corrupción. Sobre el primer asunto, se analiza cómo las pensiones y gastos sanitarios asociados a la mayor expectativa de vida incrementarán la necesidad de recursos (pp.172). La increíble novela de José Saramago, Las intermitencias de la muerte (2005), se me viene en seguida a la cabeza y no me resisto a mencionarla. La montaña rusa de emociones que atraviesa ese pueblo donde la gente deja de morir 
me resulta increíblemente sagaz y realista: de la euforia colectiva inicial, se pasa a la desesperación y el caos, a un gobierno desconcertado ante los retos financieros, demográficos y organizativos que dicho hecho supone, y a los arreglos mafiosos. El desarrollo nos enfrenta a complejas cuestiones y saca a relucir nuestras hipocresías, como el autor en todo momento con sutileza va deslizando. Por otro lado, festejo la lucidez de Carles al enfocar el problema fiscal: no se trata sólo de saber cómo y por dónde recortar (cansados estamos de tanto tijeretazo) sino de mejorar la recaudación, y ello nos conduce a luchar contra la evasión fiscal. Sobre este asunto se reclama con urgencia un incremento de inspectores de hacienda y el aprovechamiento de las nuevas tecnologías para garantizar un control en tiempo real de las actuaciones públicas y privadas (pp. 180). Pero no se trata solo de invertir mayores recursos (humanos y tecnológicos) a nivel nacional, sino también de lograr acuerdos trasnacionales destinados a eliminar paraísos fiscales y trampas vinculadas a la elusión fiscal. Para sumar a la panoplia de instrumentos citados, las políticas conductuales y las nudges prometen ser un mecanismo interesante en lo que refiere a la conducta fiscal y la lucha contra la evasión. Una investigación actual e interesante sobre este asunto se está llevando a cabo en la Universidad Autónoma de Barcelona por el equipo coordinado por José Antonio Noguera y deberíamos estar atentos a tus resultados y avances ${ }^{6}$.

Sobre el tema de la corrupción, frente a los fútiles lamentos sobre la incorregible cultura latina, resulta muy atinado que el autor recuerde que no hay nacionales mejores ni peores, la diferencia entre sus comportamientos reside en la calidad de sus instituciones públicas y su potencial para arrinconar más o menos la tendencia natural al clientelismo y a la corrupción (pp. 223). Este tratamiento sobre la corrupción seguramente puede enriquecerse también con los hallazgos y replanteamientos derivados de enfoques experimentales. Por un lado, están los trabajos de Dan Ariely (2012 y 2014) ${ }^{7}$ sobre la deshonestidad, donde se llega a la conclusión de que independientemente de nuestra cultura y a nivel de psicología individual, deseamos cometer actos deshonestos sin sentirnos deshonestos; ahora bien, cuando percibimos que nuestro grupo de pertenencia se comporta de modos deshonestos, sentimos legitimado nuestro comportamiento y avanzamos en esa línea. Los recordatorios morales y la vigilancia y castigo inmediato, incluso ante pequeñas faltas son las mejores soluciones al respecto. Por otro lado, el Banco Mundial (2015:61-62) $)^{8}$ propone la lucha contra la corrupción desde el entendido de que esta es una norma social y es la conducta esperada en ciertos escenarios y no un comportamiento anómalo, atípico o desviado. Las expectativas sociales y moldes mentales vinculados por ejemplo a la idea de lealtad o caballerosidad (kinship) y las presiones sociales que existen en una comunidad para ajustar el comportamiento (con el correlativo temor a ser un outsider) perpetúan la corrupción y la convierten en parte del "pensamiento automático" o lo esperable. De modo que, una contramedida efectiva debe ser capaz de crear nuevas situaciones donde los actores deban pensar deliberativamente sobre el comportamiento adecuado y reactivar principios morales sobre lo justo y deseable. Las instituciones importan, pero también entender la psicología de los agentes y la norma social imperante.

\footnotetext{
${ }^{6}$ 2016-2019: "Políticas públicas conductuales: aplicaciones a la lucha contra la pobreza, la fiscalidad y la salud alimentaria", Ministerio de Economía y Competitividad (MINECO), R\&D\&I National Program, Ref.: CSO2015-64740-R. http://gsadi.uab.cat/index.php/research/funded-research-projects

7 Dan Ariely (2012), Por qué mentimos...en especial a nosotros mismos, Ariel, Barcelona; y (2014), Las trampas del deseo. Como controlar los impulsos irracionales que nos llevan al error, Ariel, Barcelona. 8 World Bank, (2015), World Development Report 2015: Mind Society and Behavior. Disponible en: http://www.worldbank.org/content/dam/Worldbank/Publications/WDR/WDR\%202015/WDR-2015-FullReport.pdf.
} 
En resumidas cuentas, ¿por qué usted debería leer este libro? Para empezar, porque el libro es relevante, interesante y arriesgado, útil para políticos y gestores profesionales, y provocador para académicos. Manteniendo las ambiciones de los clásicos de las ciencias sociales, busca dar una respuesta comprometida a partir de un relato general e integrado a una pregunta tan vieja como actual: ¿qué rol compete al Estado y cómo deberían adaptarse sus estructuras para ser capaz de asumir dicho rol? Y para eso no puede sino recuperar y poner sobre la mesa las inquietantes transformaciones económicas, sociales y políticas, del mismo modo que el bueno de Schumpeter arrancó su trabajo seminal aludiendo al Marx profeta, sociólogo, economista y maestro, no porque el socialismo fuera su tema principal de investigación, sino porque para delinear su propuesta resultaba inevitable discutir con el resurgimiento de las grandes teorías.

Para seguir, porque el trabajo es un análisis que mira hacia adelante, a un futuro incierto pero a la vuelta de la esquina y la futurología es tan necesaria y urgente que en algunas latitudes ya tienen instituciones ministeriales (conducidas por mujeres) abocadas a ello ${ }^{9}$.

Por último, pero no menos importante, el texto tiene la virtud de abordar los temas e interrogantes en un lenguaje lúcido, claro y divulgativo a partir de una investigación desinhibida y con la ironía y sarcasmo que caracterizan a su autor. Por todo ello, la obra es una lectura obligada para quienes busquen huir de las inquietantes distopías de Black Mirror, así como de las ciber-utopías propias de quienes predican el poder liberador de internet o de los afectos al solucionismo tecnológico (Morozov, 2012 y 2014) ${ }^{10}$.

\section{Bibliografía}

ARIELY, D. (2012), Por qué mentimos... en especial a nosotros mismos, Ariel, Barcelona;

ARIELY, D. (2014), Las trampas del deseo. Como controlar los impulsos irracionales que nos llevan al error, Ariel, Barcelona.

DURKHEIM, E. (2003), Lecciones de sociología. Física de las costumbres y del derecho y otros escritos sobre el individualismo, los intelectuales y la democracia, Miño y Dávila editores, Buenos Aires.

MOROZOV, E. (2012), The Net Delusion: The Dark Side of Internet Freedom, Public Affairs, New York.

MOROZOV, E. (2014), To Save Everything, Click Here: The Folly of Technological Solutionism, Public Affairs, New York.

WEISS, L. (2003) States in the global economy. Bringing domestic institutions back, Cambridge University Press, Cambridge.

\footnotetext{
${ }^{9}$ Mission: The Future. Sweden Government. http://www.government.se/government-of-sweden/primeministers-office/mission-the-future/

${ }^{10}$ Morozov (2012), The Net Delusion: The Dark Side of Internet Freedom, Public Affairs; y (2014) To Save Everything, Click Here: The Folly of Technological Solutionism, Public Affairs.
} 